\title{
Consensus 2021 for medical management of type 2 diabetes from the Diabetes, Obesity, and Nutrition Working Group of the Spanish Society of Internal Medicine
}

\author{
Francisco J. Carrasco-Sánchez ${ }^{1 *}$, José M. Fernández-Rodríguez², Pedro P. Casado-Escribano ${ }^{3}$, \\ José P. Miramontes-González ${ }^{4}$, Ricardo Gómez-Huelgas ${ }^{5}$, María D. García-de-Lucas ${ }^{6}$, Javier Ena ${ }^{7}$, and \\ Juana Carretero-Gómez ${ }^{8}$ on behalf of the Diabetes, Obesity, and Nutrition Working Group of the Spanish \\ Society of Internal Medicine
}

Department of Internal Medicine, ${ }^{1}$ Hospital Universitario Juan Ramón Jiménez, Huelva; ${ }^{2}$ Hospital Carmen y Severo Ochoa, Cangas de Narcea, Asturias; ${ }^{3}$ Hospital de la Princesa, Madrid; ${ }^{4}$ Hospital Clínico Universitario de Valladolid, Valladolid; ${ }^{5}$ Hospital Regional Universitario de Málaga, Instituto de Investigación Biomédica de Málaga (IBIMA), Universidad de Málaga, Málaga; ${ }^{6}$ Hospital Costa del Sol, Marbella; ${ }^{7} \mathrm{Hospital}$ Marina Baixa, Villajoyosa, Alicante; ${ }^{8}$ Hospital Universitario de Badajoz, Badajoz. Spain

\begin{abstract}
Type 2 diabetes (T2D) is a major health concern due to its high prevalence, severe morbidity, and elevated mortality. Medical antidiabetic treatment is constantly changing and becoming more complex. Many national and international societies have published recommendations for the medical treatment of T2D focused on patients' clinical situations instead of glycemic control. However, most consensus documents offer such comprehensive information that it can be difficult to apply and effectively put into practice. This document contains the necessary 2021 update of the consensus statement about recommendations for the medical management of T2D from the Diabetes, Obesity, and Nutrition Working Group of the Spanish Society of Internal Medicine. The aim of this consensus document is to facilitate therapeutic decision-making to improve diabetes patient care. By focusing on clinical conditions such as cardiovascular risk, heart failure, diabetic kidney disease, obesity and overweight, the elderly population, risk of hypoglycemia, and history of diabetes of more than 10 years, the consensus recommends selecting antidiabetic drugs according to the best available evidence. The document prioritizes the use of glucagon-like peptide-1 receptor agonists and sodium-glucose contransporter-2 inhibitors due to their additional cardiovascular and renal benefits beyond glycemic control.
\end{abstract}

Key words: Type 2 diabetes. Treatment. Cardiovascular disease. Heart failure. Obesity. Hypoglycemia. Chronic renal disease. Elderly.

\section{Introduction}

The prevalence of type 2 diabetes (T2D) mellitus is increasing exponentially worldwide. The International Diabetes Federation (IDF) estimates that 463 million adults aged 20-79 currently suffer from diabetes, or 1 in 11 of the global population, and $50 \%$ of these (232 million) are undiagnosed. The number of individuals with diabetes is likely to rise to 578 million by 2030 , and to 700 million by $2045^{1}$.

The prevalence of diabetes in Spain, according to the di@bet.es study, is $13.8 \%$ of the adult population. Of

\section{Corrrespondence:}

*Francisco J. Carrasco-Sánchez

E-mail: franciscoj.carrasco.sspa@juntadeandalucia.es
Available online: 05-10-2021

Date of reception: 28-03-202

Date of acceptance: 07-06-2021 DOI: $10.24875 /$ SJMED.21000010 www.spanishjmed.com
Span J Med. 2021;1(3):162-170 2696-5631 / @ 2021 Sociedad Española de Medicina Interna. Published by Permanyer. This is an open access article under the CC BY-NC-ND license (http://creativecommons.org/licenses/by-nc-nd/4.0/). 
these individuals, $7.8 \%$ are aware of their T2D diagnosis (almost 3 million people) while 6\% (more than 2.3 million) are unaware that they have the disease ${ }^{2}$. The aging population, the steady rise in obesity, and the negative aspects of unhealthy diets, such as the departure from the Mediterranean diet, are factors that influence this growing prevalence of diabetes around the world. Recent data from the di@bet.es cohort reports an incidence of diabetes of 11.6 cases per 1000 people/year, of which 3.7 cases per 1000 people/year know of their diagnosis and, most concerning, 7.9 cases per 1000 people/year are unaware of their disease. Incidence varies according to age and life stages, with very low prevalence among those under 30 years and in women of fertile age, and high prevalence among the elderly $(25 \%)^{3}$. It is estimated that $35 \%$ of patients hospitalized in Internal Medicine departments in Spain receive a secondary diagnosis of diabetes ${ }^{4,5}$. These patients are typically elderly with a high comorbidity rate, and often present with established chronic kidney disease and cardiovascular disease (CVD $)^{5,6}$. Furthermore, the risk of hypoglycemia, mainly as a result of illness, is high ${ }^{7}$. The prevalence of obesity in the general population is estimated at $23 \%$, a figure similar to that found in patients treated by Internal Medicine services ${ }^{8}$. In diabetes patients, this number reaches 35\% for obesity and $70 \%$ for overweight.

There are many national and international proposals for tackling T2D therapeutically which vary in complexity and applicability in daily clinical practice. To provide practical guidance on the choice of antidiabetic drugs, the diabetes, obesity, and Nutrition Working Group of the Spanish Society of Internal Medicine (Sociedad Española de Medicina Interna [SEMI]) published its recommendations in 2020 based on a critical review of the scientific literature ${ }^{9}$. This document updates those recommendations based on new findings published in 2020.

The proposals in this document do not intend to override clinicians' professional judgment and should only be applied following a medical assessment based on the doctor's own knowledge and common practice; treatment can be adjusted according to individual preference, comorbidities, and other health-care system and patient-related factors.

The main aim of this consensus is to present a short, practical document of recommendations for antidiabetic drug therapy, striking a balance between simplicity and scientific rigor, to help clinicians to make therapeutic decisions based on the best available evidence.

\section{Material and methods}

The first part of the consensus contains recommendations based on the most frequent clinical situations that patients experience: high/very high cardiovascular risk, heart failure (HF), diabetic kidney disease (DKD), obesity and overweight, aged 75 and over, high risk of hypoglycemia, and a history of diabetes of more than 10 years (Fig. 1). The second set of recommendations concerns the administration of treatment based on the patient's initial glycated hemoglobin ( $\mathrm{HbA1c}$ ) level, and the objectives to be agreed on with the patient (Fig. 2).

This 2021 update is based on a review of the revised recommendations for T2D drug treatment published by the American Diabetes Association (ADA) in January $2021^{10}$; in addition, we ran a bibliographical search published in 2020 filtered by "T2D" in combination with: "CVD," "HF," "DKD," "obesity," "elderly," "hypoglycemia," "glucagon-like peptide-1 receptor agonists GLP-1RAs," "sodium-glucose contransporter-2 (SGLT2) inhibitors," "DPP4 inhibitors," and "insulin."

The first version of this consensus was published in 2020 in Revista Clínica Española (online, June 2020) ${ }^{9}$. This updated version contains additional information from four clinical trials and two systematic reviews ${ }^{11-17}$.

We used standard ADA classifications to test the quality of the evidence: A (clear evidence from randomized controlled trials); B (evidence from observational studies); C (evidence from non-controlled studies); and E (a consensus of experts or clinical experience) ${ }^{18}$. Each principal recommendation in our consensus is categorized and stated within parentheses by one of these letters.

The consensus draft was revised and approved by a committee of experts from SEMl's diabetes, obesity, and Nutrition Working Group, and a final consensus reached.

\section{Results and recommendations}

Metformin and lifestyle changes are still the main recommendations for treating $\mathrm{T} 2 \mathrm{D}$ in the absence of intolerance or contraindication. In $75-80 \%$ of patients participating in cardiovascular safety studies, metformin was administered in combination with other antidiabetic drugs that were the focus of those studies (A).

\section{High and very high cardiovascular risk}

CVD in people with diabetes begins before diabetes is diagnosed; this concept, known as the 


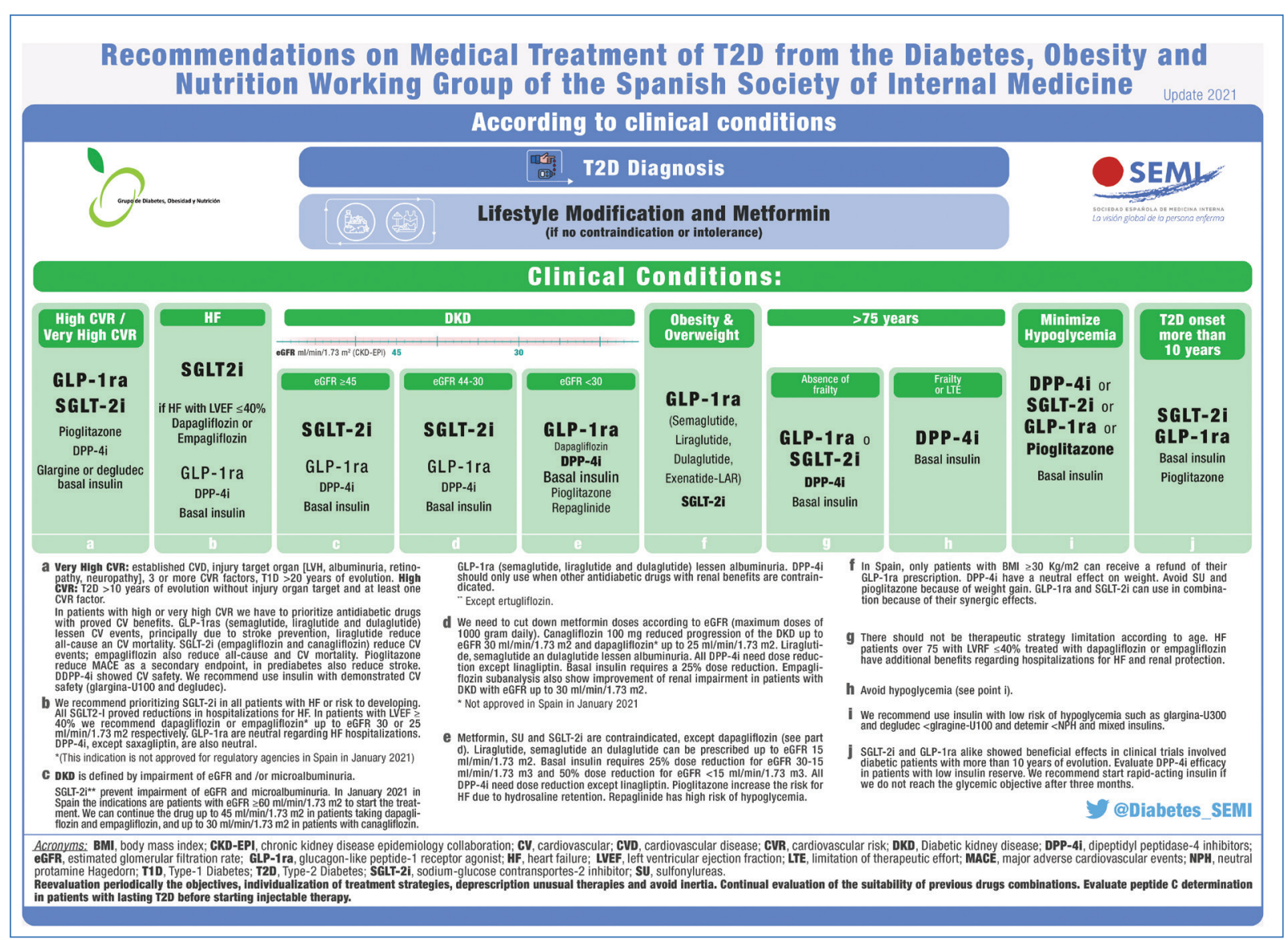

Figure 1. Recommendations on medical treatment of type 2 diabetes from the Diabetes, Obesity, and Nutrition Working Group of the Spanish Society of Internal Medicine.

cardiovascular continuum, advises that the diabetic patient be classified as high or very high cardiovascular risk regardless of the presence of established CVD. Patients are classified as high cardiovascular risk if they have a T2D history of more than 10 years in the absence of target organ damage, and with at least one additional cardiovascular risk factor. Diabetic patients are classified as very high cardiovascular risk if they have target organ damage, three or more additional cardiovascular risk factors, or established CVD ${ }^{19}$.

Metformin is considered to be safe even for high and very high cardiovascular risk patients ${ }^{20}$ (C). GLP-1RAs and SGLT-2 inhibitors are the drugs of choice, as their use is associated with a reduction in CVD events as compared to placebo $(A)$.

In the LEADER trial, liraglutide, a GLP-1RA, reduced the primary combined endpoint of major adverse cardiovascular events (MACE) (hazard ratio [HR]: 0.87; 95\% confidence interval $[\mathrm{Cl}]: 0.78-0.97 ; p=0.01$ ). In the ungrouped analysis, the relative risk reduction
(RRR) was $22 \%(p=0.007)$ for CV mortality and $15 \%$ $(p=0.02)$ for total mortality ${ }^{21}$. In the SUSTAIN- 6 study, semaglutide reduced MACE (HR 0.74; $95 \% \mathrm{Cl}$ : 0.58$0.95 ; p=0.02)$ with $39 \% \operatorname{RRR}(p=0.04)$ for stroke 22 . Similarly, in the REWIND study, dulaglutide reduced MACE (HR 0.88; 95\% Cl: 0.79-0.99; $p=0.026$ ) with $24 \%$ RRR $(p=0.017)$ for stroke ${ }^{23}$. Lixisenatide ${ }^{24}$ and exenatide $\operatorname{LAR}^{25}$ were neutral compared to standard treatment.

Regarding SGLT2 inhibitors, empagliflozin (EMPAREG-OUTCOME trial) also reduced MACE (HR 0.86; $95 \%$ Cl: $0.74-0.99 ; p=0.04)$ with a $38 \% \operatorname{RRR}(p<0.001)$ for CV mortality and $32 \%(p<0.001)$ for total mortality $^{26}$. In the CANVAS study, canagliflozin reduced MACE (HR 0.86; 95\% Cl: 0.75-0.97 p = 0.02), not reaching statistical significance for the individual cardiovascular outcome components ${ }^{27}$. The DECLARE study on dapagliflozin found no statistical significance in the reduction of $\mathrm{MACE}^{28}$. 


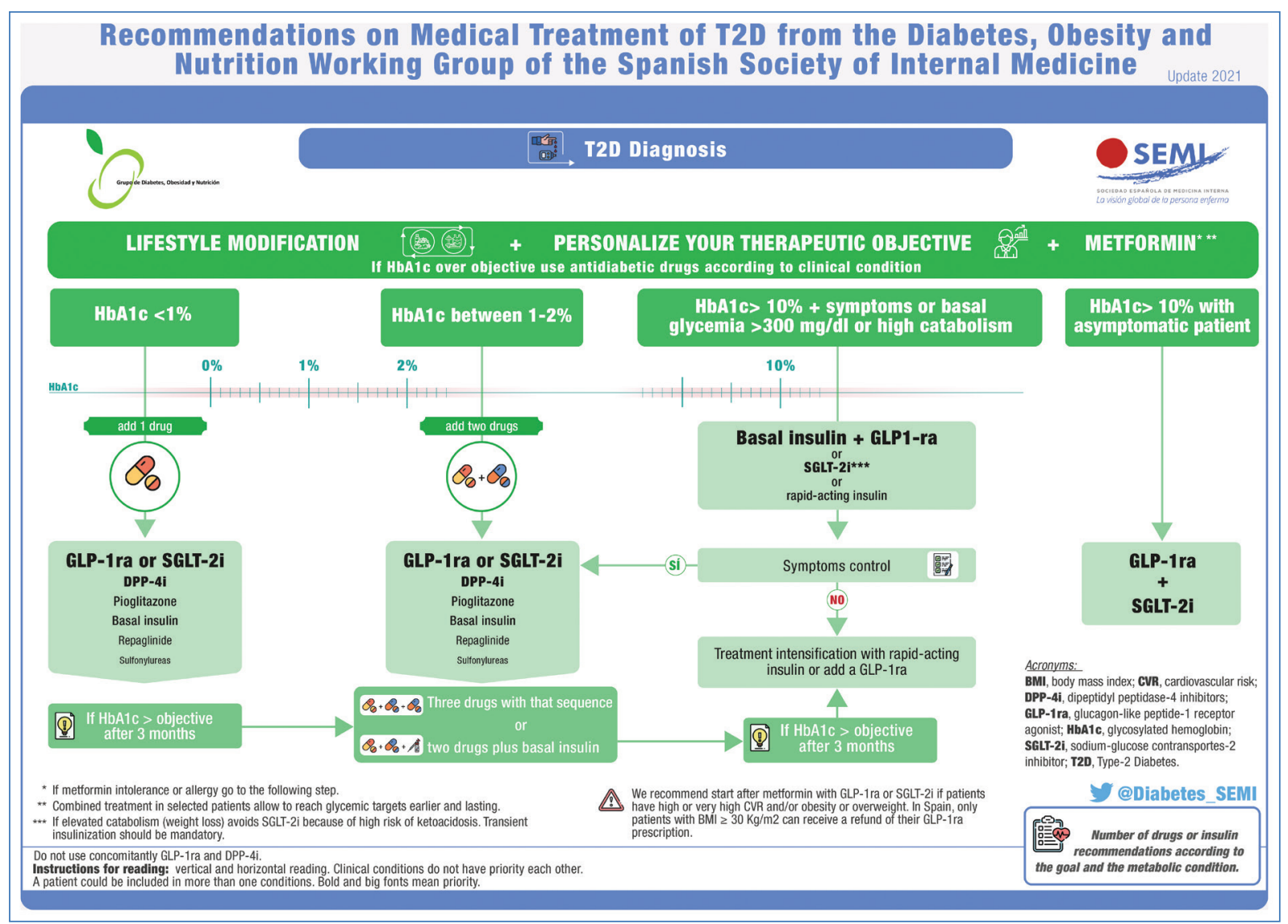

Figure 2. Recommendations on medical treatment of type 2 diabetes from the Diabetes, Obesity, and Nutrition Working Group of the Spanish Society of Internal Medicine.

The VERTIS-CV trial with ertugliflozin showed no reduction in cardiovascular events (HR 0.97; 95.6\% Cl: $0.85-1.11 ; p<0.001$ for non-inferiority) in a population similar to that of the EMPA-REG-OUTCOME study ${ }^{11}$.

The PROactive study on pioglitazone found a $16 \%$ RRR $(p=0.027)$ in MACE as a secondary objective ${ }^{29}$. In a pre-diabetic population, treatment with pioglitazone was linked to a $24 \%$ RRR ( $p=0.007)$ for the combined variable of stroke and/or heart $\operatorname{attack}^{30}(A)$.

The CV safety of dipeptidyl peptidase-4 (iDPP4) enzyme inhibitors was not inferior to standard antidiabetic treatment (A). Although there are no trials directly addressing the CV safety of vildagliptin, a meta-analysis of studies supports its neutrality $(B)^{31}$. The CAROLINA study on linagliptin was neutral versus glimepiride for MACE, with a higher rate of hypoglycemia in the glimepiride group $(A)^{32}$. For basal insulin, glargine-U100 demonstrated CV safety in the ORIGIN study ${ }^{33}$; the DEVOTE study compared insulin degludec to glargine-U100 and no inferiority was found $(A)^{34}$ (Fig. 1).

\section{Heart failure}

SGLT2 inhibitors remain the drug of choice for patients with $\mathrm{HF}$ or those at risk of developing it $(\mathrm{A})$. In the aforementioned cardiovascular safety studies, empagliflozin (HR 0.65; 95\% Cl: 0.50-0.85; $p=0.002$ ), canagliflozin (HR 0.67; 95\% Cl: 0.52-0.87; $\mathrm{p}<0.001$ ), dapagliflozin (HR 0.73; 95\% Cl: 0.61-0.88; $p=0.0005$ ), and ertugliflozin (HR 0.70; 95\% Cl: 0.54-0.90; $p=0.006$ ) were indicated for a significant reduction in hospitalizations for $\mathrm{HF}^{11,26-28}$.

The DAPA-HF study showed that dapagliflozin reduced the primary combined endpoint of cardiovascular mortality, hospitalizations for HF, and/or emergency room visits for HF in patients with reduced ejection fraction (EF $\leq 40 \%$ ) and estimated glomerular filtration rate $(\mathrm{eGFR}) \geq 30 \mathrm{~mL} / \mathrm{min} / 1.73 \mathrm{~m}^{2}$ regardless of the presence of diabetes (HR $0.74 ; 95 \% \mathrm{Cl}$ : 0.65 $0.85 ; p=0.00001)^{35}$. Similarly, in the EMPERORREDUCED study, empagliflozin reduced the primary combined endpoint of cardiovascular mortality, HF 
hospitalizations with $\mathrm{EF} \leq 40 \%$ and eGFR $\geq 20 \mathrm{~mL} / \mathrm{min} / 1.73 \mathrm{~m}^{2}$ in patients with and without diabetes (HR 0.75; 95\% Cl: 0.65-0.86; $p<0.001)^{13}$.

GLP-1RAs were neutral for HF hospitalizations, except for albiglutide (HR 0.71; 95\% Cl: 0.53-0.94; $p<0.0001)$ which reduced them ${ }^{36}(A)$. iDPP4s were neutral, except for saxagliptin (HR 1.27; 95\% Cl: 1.07-1.51; $p=0.007$ ), for HF hospitalizations ${ }^{37}$. Basal insulin analogs were neutral for HF hospitalizations in the above-mentioned studies ${ }^{33,34}$ (A). Pioglitazone was contraindicated as it was associated with a rise in HF hospitalizations due to hydrosaline retention (A) (Fig. 1).

\section{Diabetic kidney disease}

All the studies (A) consistently reported that SGLT2 inhibitors reduce the risk of DKD progression, defined as the need for dialysis, kidney transplant or death by kidney failure (HR 0.67; 95\% Cl: 0.52-0.86; $p=0.0019$ ), progression to terminal kidney disease (HR 0.65; 95\% Cl: 0.53-0.81; $p<0.0001$ ), and severe kidney injury (HR 0.75 ; $95 \% \mathrm{Cl}: 0.66-0.85 ; p<0.0001)$. In the eGFR subgroups analysis, the prevention of renal function deterioration and albuminuria decrease is persistent even with eGFR of $30-45 \mathrm{~mL} / \mathrm{min} / 1.73 \mathrm{~m}^{2}(\mathrm{C})$. This effect occurs regardless of the presence of microalbuminuria and the use of renin-angiotensin system blockers ${ }^{38}$.

Two studies assessed the renal benefits of SGLT2 inhibitors combined with renin-angiotensin system blockers. Both the CREDENCE study ${ }^{39}$ with canagliflozin $100 \mathrm{mg}$ in T2D, in which $60 \%$ of its patients had eGFR $30-59 \mathrm{~mL} / \mathrm{min} / 1.73 \mathrm{~m}^{2}$, and the DAPA-CKD study ${ }^{12}$ with dapagliflozin $10 \mathrm{mg}$ in patients with or without diabetes, in which almost $90 \%$ of the patients had eGFR 25-59 mL/min/1.73 $\mathrm{m}^{2}$, showed a significant reduction in DKD progression (A). The presence of DKD was less evident in the DECLARE-TIMI 58, CANVAS, and EMPA-REG OUTCOME studies, at $8 \%$, $20 \%$, and $26 \%$, respectively.

Regarding GLP-1RAs, liraglutide (HR 0.78; $95 \% \mathrm{Cl}$ : $0.67-0.92 ; p=0.003$ ), semaglutide (HR $0.64 ; 95 \% \mathrm{Cl}$ : $0.46-0.88 ; p=0.006$ ), and dulaglutide (HR $0.85 ; 95 \%$ Cl: $0.77-0.93 ; p=0.0004$ ) reduced renal events (eGFR deterioration, microalbuminuria, and renal death) ${ }^{36}(A)$.

Other antidiabetic drugs showed no ability to prevent renal function deterioration. The use of metformin requires dose reduction in patients with eGFR $<45 \mathrm{~mL}$ / $\mathrm{min} / 1.73 \mathrm{~m}^{2}$, and DPP4 inhibitors (except linagliptin) require dose adjustment depending on the eGFR.
Pioglitazone is not recommended due to the risk of hydrosaline retention $(A)$.

Metformin and sulfonylureas are contraindicated for eGFR $<30 \mathrm{~mL} / \mathrm{min} / 1.73 \mathrm{~m}^{2}$. SGLT2 inhibitors should not be used with eGFR $<30 \mathrm{~mL} / \mathrm{min} / 1.73 \mathrm{~m}^{2}$ but, as already mentioned, dapagliflozin continues to have renal benefits up to eGFR $25 \mathrm{~mL} / \mathrm{min} / 1.73 \mathrm{~m}^{2} 12$ (A). Liraglutide, semaglutide, and dulaglutide can be used down to eGFR $15 \mathrm{~mL} / \mathrm{min} / 1.73 \mathrm{~m}^{2}$ to continued good cardiovascular and renal effect (A). Basal insulin requires a $25 \%$ reduction for eGFR $15-30 \mathrm{~mL} / \mathrm{min} / 1.73$ $\mathrm{m}^{2}$ and $50 \%$ for eGFR $<15 \mathrm{~mL} / \mathrm{min} / 1.73 \mathrm{~m}^{2}$. Repaglinide can be used with advanced DKD patients although it could increase the risk of hypoglycemia.

The recent FIDELIO-DKD study assessed the effect of finerenone, a selective nonsteroidal mineralocorticoid receptor antagonist, on renal and cardiovascular events in patients with kidney disease and T2D in optimum treatment with renin-angiotensin system blockers. Patients in the trial presented an albumin-creatinine ratio of $30-300 \mathrm{mg} / \mathrm{g}$, and eGFR of $25-60 \mathrm{~mL} /$ $\min / 1.73 \mathrm{~m}^{2}$. Finerenone significantly reduced the primary composite outcome (renal failure, eGFR reduction $\geq 40 \%$ of basal, and/or renal death) (HR 0.82; $95 \% \mathrm{Cl}$ : $0.73-0.93 ; p=0.001$ ). It also reduced secondary outcomes, such as MACE and hospitalizations for HF (HR 0.86 ; $95 \% \mathrm{Cl}: 0.75-0.99 ; p=0.034)^{16}$. The results were similar in the presence or absence of established CVD, $(p \text {-value for the interaction } 0.85)^{14}(\mathrm{~A})$ (Fig. 1).

\section{Overweight and obesity}

Overweight and obesity are linked to an increase in cardiovascular events, HF, and total mortality ${ }^{40}$. GLP1RAs are the drugs of choice. Weight reduction for the different drugs varies, with the hierarchy ranging from greater to lesser weight loss: semaglutide, liraglutide, dulaglutide, exenatide LAR, and lixisenatide (A).

SGLT2 inhibitors are associated with reduction in body weight, although of the lower intensity and less enduring effect in the long term (A). The combination of GLP-1RAs and SGLT2 inhibitors is recommended to achieve weight loss objectives (E).

Pioglitazone, sulfonylureas, glinides, and basal insulin analogs are linked to body weight gain ${ }^{41}$. The iDPP4s are neutral (A). The role of antidiabetic drugs in the treatment of non-alcoholic fatty liver disease (NAFLD) is currently under study, and could benefit patients receiving treatment with pioglitazone, GLP-1RAs, and/ or SGLT2 inhibitors ${ }^{42}$ (Fig. 1). 


\section{Patients over 75 years of age}

Elderly patients are more vulnerable to the deleterious effects of hypoglycemia and other secondary effects, so the goals for controlling their blood glucose levels should be less stringent. Nevertheless, many of the aforementioned studies include additional benefits for elderly patients in terms of cardiovascular, renal, and HF prevention. The EMPA-REG OUTCOME study in patients $>75$ years reported a reduction in cardiovascular mortality (HR $0.55 ; 95 \%$ Cl: 0.32-0.94), HF hospitalizations (HR 0.45; $95 \% \mathrm{Cl}$ : $0.22-0.89$ ), and renal events (HR 0.54; $95 \% \mathrm{Cl}$ : 0.370.79 ) that was higher than for the general population $^{43}$. In the CANVAS study, the results were similar in patients > 65 years (HR 0.80; 95\% Cl: 0.67-0.95) ${ }^{27}$. The GLP-1RAs also showed beneficial effects in elderly patients ${ }^{44}$.

In the DAPA-HF trial, patients $>75$ years benefited most from the drop in hospitalizations for $\mathrm{HF}$ and/or cardiovascular mortality (HR 0.68 ; $95 \% \mathrm{Cl}$ : $0.53-0.88$; $p=0.003)$ with fewer secondary effects than the placebo, especially in volume depletion and renal injury ${ }^{45}$ (C). The EMPEROR-REDUCED trial found similar benefits for patients $>75$ years $(p \text { for interaction }=0.54)^{17}$ (C). As most findings for the elderly come from sub-studies of clinical trials, the level of evidence is classified as "C."

Any clinical assessment of elderly T2D patients should take into account functional, cognitive, and social factors. Age is not the only factor to consider in antidiabetic treatment, which should be less intensive for patients with functional, cognitive, and social impediments and/or poor prognosis. It is essential that the patient not develop acute hypoglycemia, so drugs that present a low risk of developing this condition should be administered; if insulin is required, it should be the safest form for this type of patient. Further details can be found in the Spanish Society of Internal Medicine's Consensus on T2D treatment for the elderly $^{46}$ (Fig. 1).

\section{Hypoglycemia}

Drugs with non-insulin dependent actions exhibit a low risk of hypoglycemia and are thus recommended: metformin, GLP-1RAs, SGLT2 inhibitors, and iDPP4 (E). Both glargine U300 and degludec achieve lower incidence of hypoglycemia as compared to levemir and glargine $\mathrm{U} 100^{34,47}$ (A) (Fig. 1).

\section{Patients with long-term diabetes (> 10 years)}

SGLT2 inhibitors ${ }^{26-28}$ and GLP-1RAs ${ }^{21-23}$ have been shown to be beneficial in cardiovascular safety studies in T2D patients who have had diabetes for 10 years or longer, as opposed to studies with sulfonylureas, metformin, or basal insulin analogs ${ }^{48-51}$ (A) (Fig. 1).

\section{Treatment according to $\mathrm{HbA1C}$}

Metformin continues to be the foundation of any antidiabetic treatment. This document recommends the number of drugs to be administered according to initial $\mathrm{HbA} 1 \mathrm{c}$ and personalized therapeutic goals $(\mathrm{E})$.

GLP-1RAs and/or SGLT2 inhibitors are recommended as a second line of treatment after metformin for the cardiovascular and renal benefits mentioned previously (A). Basal insulin analogs can be used whenever required, according to metabolic control, especially if insulin reserves are low, blood glucose level $>300 \mathrm{mg} /$ $\mathrm{dL}$, cardinal symptoms of high catabolism or $\mathrm{HbA} 1 \mathrm{c}$ $>10 \%$ with hyperglycemia symptoms, or when there is a contraindication or intolerance to other therapies $(E)$ (Fig. 2).

\section{Discussion}

This consensus gathers the recommendations of the diabetes, obesity, and nutrition working group of the SEMI for decision-making regarding drugs for T2D treatment, based on the best available evidence up to January 2021. Although this information is primarily for Internal Medicine practitioners, it can be used by clinicians in other specialties who deal with T2D patients at any level within the health system. The high prevalence and increased incidence of T2D means that doctors of any discipline might need to treat such patients across a range of scenarios in their daily clinical practice.

The first part of the algorithm should be interpreted horizontally, then vertically: select the patient's clinical situation or situations (horizontal) then decide which drug to use in this situation (vertical) (Fig. 1). Doctors must always evaluate the drug's contraindications, the dose to administer, and whether the indication conforms to the medical specifications, to avoid therapeutic inertia. The document offers some recommendations not included in the medical specification indications, at least in Spain, on eGFR threshold for initial use of most SGLT2 inhibitors, or regarding BMI for GLP-1RAs. 
However, solid evidence from recent clinical trials suggests that these indications could soon be included following review by the health authorities.

In the recommendations for reducing cardiovascular events, we found no difference in the use of GLP-1RAs among patients with/without established CVD, as opposed to other consensuses. Current treatment of cardiovascular risk should focus on the cardiovascular continuum and avoid the discussion on primary and secondary prevention ${ }^{52}$. In fact, various trials with GLP1RAs apply different criteria when classifying patients with or without established CVD. SUSTAIN-6 and LEADER include vascular stenosis $>50 \%$ at the coronary, carotid, and periphery level, moderate renal insufficiency, or stage 2/3 HF as established CVD. In contrast, these patients were not defined as having established CVD in the REWIND study ${ }^{53}$.

Although the overall perception of SGLT2 inhibitors would suggest a class effect in cardiovascular event reduction, the DECLARE-TIMI study ${ }^{28}$ with dapagliflozin did not reduce MACE in the total population; it did so in patients with a prior history of acute myocardial infarction ${ }^{54}$. The recent VERTIS-CV trial with ertugliflozin also failed to achieve a significant reduction in cardiovascular events ${ }^{11}$.

The DECLARE-TIMI trial results were supposedly explained by the fact that there were fewer patients with established CVD and advanced DKD as compared to other studies with SGLT2 inhibitors. However, this is not a valid argument for the VERTIS-CV trial as almost the entire study population had established CVD. Thus, the class effect of reducing cardiovascular events in T2D patients is at least questionable, and the recommendation for SGLT2 inhibitor use in T2D patients should focus on those patients who have experienced this reduction. In contrast, the results of the study with dapagliflozin are the easiest to generalize ${ }^{15}$.

When considering mechanisms of protection, SGLT2 inhibitors seem to generate cardiorenal benefits through hemodynamic mechanisms while GLP-1RAs would have anti-atherosclerosis effects; thus, both mechanisms are complementary, with additive effects on the cardiovascular risk continuum.

SGLT2 inhibitors have a class effect for reducing hospitalizations for HF. However, the percentage of HF patients before the initial studies was small, so the evidence is more robust for preventing the development of $\mathrm{HF}^{55}$. Regarding established HF, both dapagliflozin and empagliflozin show a reduction in hospitalizations and/or cardiovascular mortality in $\mathrm{HF}$ patients and reduced $(<40 \%)$ EF regardless of the presence of diabetes ${ }^{17}$.

Despite the neutral results in the CAROLINA study ${ }^{32}$, with a rise in hypoglycemia in the glimepiride treatment arm, sulfonylureas are not recommended for patients with high or very high cardiovascular risk as many clinical trials and observational studies have described an increased CV risk associated with the use of these antidiabetic drugs ${ }^{56}$.

For DKD, current indications in the medical specifications in Spain continue to establish the threshold for SGLT2 inhibitors (except canagliflozin) at eGFR $>60 \mathrm{~mL} / \mathrm{min} / 1.73 \mathrm{~m}^{2}$ for starting treatment, with a maintenance dosage at eGFR $45 \mathrm{~mL} / \mathrm{min} / 1.73 \mathrm{~m}^{2}$. Based on the results of the CREDENCE study ${ }^{39}$, which included patients with eGFR $30 \mathrm{~mL} / \mathrm{min} / 1.73 \mathrm{~m}^{2}$, canagliflozin 100 can be administered to start treatment at eGFR $30 \mathrm{~mL} / \mathrm{min} / 1.73 \mathrm{~m}^{2}$, and as a maintenance dosage for patients already in treatment even if the eGFR is lower. Results from the DAPA-CKD study support the use of dapagliflozin down to an eGFR of $25 \mathrm{~mL} / \mathrm{min} / 1.73$ $\mathrm{m}^{2}$ (this indication was not included in the medical specification when preparing this consensus). These findings emphasize the importance of most SGLT2 inhibitors in affording cardiorenal protection to moderate to severe DKD patients. More analyses of ertugliflozin for DKD patients are required to support its use to treat this disease. Although the results are promising, finerenone is not yet available for use in Spain.

GLP-1RAs reduce body weight for overweight and obese patients, but its use in Spain is only approved and financed for $\mathrm{BMI} \geq 30 \mathrm{~kg} / \mathrm{m}^{2}$.

When treating elderly T2D patients, it is important to combine a functional, cognitive, and social approach with the clinical assessment. Regardless of age, patients who can function adequately should benefit from the same treatments and blood glucose control goals as younger subjects, with chronological age being no barrier to treatment. However, in patients with deteriorating functional and cognitive faculties or poor prognosis, the priority should be limitation of pharmacological treatment. In these patients, it is important to prevent the development of acute symptomatic hyperglycemia, and even more importantly, to avoid hypoglycemia. Physicians should use drugs with a low risk of producing hypoglycemia. In patients who need insulin, we should prioritize the new generation of basal insulins with low risk of hypoglycemia ${ }^{46}$.

Regarding a blood glucose level approach (Fig. 2), it is important to set a HbA1c patient-centered goal. Lifestyle measures and metformin alike continue to be 
the basis of any therapeutic plan. The algorithm helps us predict the use of one, two, or three drugs to achieve those therapeutic goals. Although insulinization is traditionally recommended for patients with $\mathrm{HbA} 1 \mathrm{c}>10 \%$ on diagnosis, GLP-1RAs and/or SGLT2 inhibitors together with metformin can often achieve correct metabolic control and may avoid the use of insulin, even temporarily. Patients with cardinal symptoms and/or hyperglycemia $>300 \mathrm{mg} / \mathrm{dL}$ should not be initially treated with SGLT2 inhibitors due to the risk of euglycemic ketoacidosis.

It is essential to identify insulinopenic patients who need substitution therapy with insulin, thus predicting metabolic failure if we initiate other therapies. However, the objective of this consensus is not to provide recommendations for basal bolus insulin regimen therapy and intensification with rapid insulin analogs in multiple doses.

The ultimate aim of this consensus is to provide guidelines for correct treatment to improve prognosis and reduces complications in T2D patients in any area of healthcare.

The advantage of this document is that it is clear, concise, and simple to use in daily clinical practice. Its main drawback is that it cannot provide in-depth answers to highly specific and/or special clinical situations. However, the balance between simplicity and scientific rigor means it can be widely applied as a consensus across the scientific and health-care community.

\section{Author contribution statements}

C-S F.J. coordinated the project. F-R J.M., C-G J., and C-S F.J. conceived of the idea, analyzed the data, wrote the manuscript, and designed the algorithms. All authors participated in the discussion and contributed to the final manuscript.

\section{Funding}

The project was supported by the Spanish Society of Internal Medicine.

\section{Conflicts of interest}

The authors declare no conflicts of interest regarding this article.

\section{References}

1. International Diabetes Federation. Diabetes Atlas. $9^{\text {th }}$ ed. Brussels, Belgium: International Diabetes Federation; 2019. Available from: https:// www.diabetesatlas.org/upload/resources/material/20200302_133351 IDFATLAS9e-final-web.pdf.

2. Soriguer F, Goday A, Bosch-Comas A, Bordiú E, Calle-Pascual A, Carmena $\mathrm{R}$, et al. Prevalence of diabetes mellitus and impaired glucose regulation in Spain: the Di@bet.es study. Diabetologia. 2012;55:88-93.

3. Rojo-Martínez G, Valdés S, Soriguer F, Vendrell J, Urrutia I, Montanya E, et al. Incidence of diabetes mellitus in Spain as results of the nation-wide cohort di@bet.es study. Sci Rep. 2020;10:110.

4. Zapatero A, Gómez-Huelgas R, González N, Canora J, Asenjo A, Hinojosa J, et al. Frequency of hypoglycemia and its impact on length of stay, mortality, and short-term readmission in patients with diabetes hospitalized in internal medicine wards. Endocr Pract. 2014;20:870-5.

5. Ena J, Gómez-Huelgas R, Romero-Sánchez M, Gaviria AZ, Calzada-Valle A, Varela-Aguilar JM, et al. Hyperglycemia management in patients admitted to internal medicine in Spain: a point-prevalence survey examining adequacy of glycemic control and guideline adherence. Eur J Intern Med. 2015;26:392-8.

6. Zapatero-Gaviria A, Gómez-Huelgas R, Canora-Lebrato J, Ena-Muñoz J, Romero-Sánchez M, Mendez-Bailón M, et al. Analysis of hospitalizations by cardiovascular disease in the population with diabetes in Spain. Rev Clin Esp. 2019;219:124-9.

7. Ena J, Gaviria AZ, Romero-Sánchez M, Carretero-Gómez J, Carrasco-Sánchez FJ, Segura-Heras JV, et al. Derivation and validation model for hospital hypoglycemia. Eur J Intern Med. 2018;47:43-8.

8. Carretero Gómez J, Arévalo Lorido JC, Gómez Huelgas R, Vidal MT, Tembra MS, Aguilar JM, et al. Prevalencia de obesidad según la estadificación de Edmonton en las consultas de medicina interna. Resultados del estudio OBEMI. Rev Clin Esp. 2017;217:71-8.

9. Carrasco-Sánchez FJ, Fernández-Rodríguez JM, Ena J, Gómez-Huelgas R, Carretero-Gómez J. Medical treatment of Type 2 diabetes mellitus: recommendations of the diabetes, obesity and nutrition group of the Spanish society of internal medicine. Rev Clin Esp. 2021;221:101-8.

10. Care D, Suppl SS. Pharmacologic approaches to glycemic treatment: standards of medical care in diabetes 2021. Diabetes Care. 2021;44:S111-24.

11. Cannon CP, Pratley R, Dagogo-Jack S, Mancuso J, Huyck S, Masiukiewicz $U$, et al. Cardiovascular outcomes with ertugliflozin in Type 2 diabetes. N Engl J Med. 2020;383:1425-35.

12. Heerspink HJ, Stefánsson BV, Correa-Rotter R, Chertow GM, Greene T, Hou FF, et al. Dapagliflozin in patients with chronic kidney disease. N Engl J Med. 2020;383:1436-46.

13. Packer M, Anker SD, Butler J, Filippatos G, Pocock SJ, Carson P, et al. Cardiovascular and renal outcomes with empagliflozin in heart failure. N Engl J Med. 2020;383:1413-24.

14. Filippatos G, Anker SD, Agarwal R, Pitt B, Ruilope LM, Rossing P, et al. Finerenone and cardiovascular outcomes in patients with chronic kidney disease and Type 2 diabetes. Circulation. 2021;143:540-52.

15. Castellana M, Procino F, Sardone R, Trimboli P, Giannelli G. Generalizability of sodium-glucose co-transporter-2 inhibitors cardiovascular outcome trials to the Type 2 diabetes population: a systematic review and meta-analysis. Cardiovasc Diabetol. 2020;19:1-10.

16. Bakris GL, Agarwal R, Anker SD, Pitt B, Ruilope LM, Rossing P, et al. Effect of finerenone on chronic kidney disease outcomes in Type 2 diabetes. N Engl J Med. 2020;383:2219-29.

17. Zannad F, Ferreira JP, Pocock SJ, Anker SD, Butler J, Filippatos G, et al. SGLT2 inhibitors in patients with heart failure with reduced ejection fraction: a meta-analysis of the EMPEROR-Reduced and DAPA-HF trials. Lancet. 2020;396:819-29.

18. Introduction: standards of medical care in diabetes-2020. Diabetes Care. 2020;43:S1-2

19. Cosentino F, Grant PJ, Aboyans V, Bailey CJ, Ceriello A, Delgado V, et al.; ESC Scientific Document Group. 2019 ESC Guidelines on diabetes, pre-diabetes, and cardiovascular diseases developed in collaboration with the EASD. Eur Heart J. 2020 Jan 7;41(2):255-323. Erratum in: Eur Heart J. 2020;41(45):4317.

20. Griffin SJ, Leaver JK, Irving GJ. Impact of metformin on cardiovascular disease: a meta-analysis of randomised trials among people with Type 2 diabetes. Diabetologia. 2017;60:1620-9.

21. Marso SP, Daniels GH, Brown-Frandsen K, Kristensen P, Mann JF, Nauck MA, et al. Liraglutide and cardiovascular outcomes in Type 2 diabetes. N Engl J Med. 2016;375:311-22.

22. Marso SP, Bain SC, Consoli A, Eliaschewitz FG, Jódar E, Leiter LA, et al. Semaglutide and cardiovascular outcomes in patients with Type 2 diabetes. N Engl J Med. 2016;375:1834-44.

23. Gerstein HC, Colhoun HM, Dagenais GR, Diaz R, Lakshmanan M, Pais $P$, et al. Dulaglutide and cardiovascular outcomes in Type 2 diabetes (REWIND): a double-blind, randomised placebo-controlled trial. Lancet. 2019;394:121-30.

24. Pfeffer MA, Claggett B, Diaz R, Dickstein K, Gerstein HC, Køber LV, et al. Lixisenatide in patients with Type 2 diabetes and acute coronary syndrome. N Engl J Med. 2015;373:2247-57.

25. Holman RR, Bethel MA, Mentz RJ, Thompson VP, Lokhnygina Y, Buse JB, et al. Effects of once-weekly exenatide on cardiovascular outcomes in Type 2 diabetes. N Engl J Med. 2017;377:1228-39. 
26. Zinman B, Wanner C, Lachin JM, Fitchett D, Bluhmki E, Hantel S, et al Empagliflozin, cardiovascular outcomes, and mortality in Type 2 diabetes. N Engl J Med. 2015;373:2117-28.

27. Neal B, Perkovic V, Mahaffey KW, Matthews DR. Canagliflozin and cardiovascular and renal events in Type 2 diabetes. N Engl J Med. 2017;377:644-57.

28. Wiviott SD, Raz I, Bonaca MP, Mosenzon O, Kato ET, Cahn A, et al. Dapagliflozin and cardiovascular outcomes in Type 2 diabetes. $\mathrm{N}$ Engl $J$ Med. 2019;380:347-57.

29. Dormandy JA, Charbonnel B, Eckland DJ, Erdmann E, Massi-Benedetti M, Moules IK, et al. Secondary prevention of macrovascular events in patients with Type 2 diabetes in the PROactive study (PROspective pioglitAzone clinical trial in macrovascular events): a randomised controlled trial. Lancet. 2005;366:1279-89.

30. Kernan WN, Viscoli CM, Furie KL, Young LH, Inzucchi SE, Gorman M, et al. Pioglitazone after ischemic stroke or transient ischemic attack. N Engl J Med. 2016;374:1321-31.

31. McInnes G, Evans M, Del Prato S, Stumvoll M, Schweizer A, Lukashevich $\mathrm{V}$, et al. Cardiovascular and heart failure safety profile of vildagliptin: a meta-analysis of 17000 patients. Diabetes Obes Metab. 2015;17: 1085-92.

32. Rosenstock J, Kahn SE, Johansen OE, Zinman B, Espeland MA, Woerle $\mathrm{HJ}$, et al. Effect of linagliptin vs glimepiride on major adverse cardiovascular outcomes in patients with Type 2 diabetes: the CAROLINA randomized clinical trial. JAMA. 2019;322:1155-66

33. Gerstein HC, Bosch J, Dagenais GR, Díaz R, Jung H, Maggioni AP, et al Basal insulin and cardiovascular and other outcomes in dysglycemia N Engl J Med. 2012;367:319-28.

34. Marso SP, Mcguire DK, Zinman B, Poulter NR, Emerson SS, Pieber TR, et al. Efficacy and safety of degludec versus Glargine in Type 2 Diabetes. N Engl J Med. 2017;377:723-32.

35. McMurray JJ, Solomon SD, Inzucchi SE, Køber L, Kosiborod MN, Martinez $F A$, et al. Dapagliflozin in patients with heart failure and reduced ejection fraction. N Engl J Med. 2019;381:1995-2008.

36. Kristensen SL, Rørth R, Jhund PS, Docherty KF, Sattar N, Preiss D, et al Cardiovascular, mortality, and kidney outcomes with GLP-1 receptor agonists in patients with Type 2 diabetes: a systematic review and meta-analysis of cardiovascular outcome trials. Lancet Diabetes Endocrinol. 2019;8587:1-10.

37. Singh AK, Singh R. Heart failure hospitalization with DPP-4 inhibitors: a systematic review and meta-analysis of randomized controlled trials. Indian J Endocrinol Metab. 2019:23:128-33.

38. Neuen BL, Young T, Heerspink HJ, Neal B, Perkovic V, Billot L, et al. SGLT2 inhibitors for the prevention of kidney failure in patients with type 2 diabetes: a systematic review and meta-analysis. Lancet Diabetes Endocrinol. 2019;7:845-54

39. Perkovic V, Jardine MJ, Neal B, Bompoint S, Heerspink HJ, Charytan DM et al. Canagliflozin and renal outcomes in Type 2 diabetes and nephropathy. N Engl J Med. 2019;380:2295-306.

40. Costanzo P, Cleland JG, Pellicori P, Clark AL, Hepburn D, Kilpatrick ES et al. The obesity paradox in Type 2 diabetes mellitus: relationship of body mass index to prognosis: a cohort study. Ann Intern Med. 2015;162:610-8.

41. Care D, Suppl SS. 9. Pharmacologic approaches to glycemic treatment: standards of medical care in diabetes-2020. Diabetes Care. 2020;43: S98-110.
42. Ranjbar G, Mikhailidis DP, Sahebkar A. Effects of newer antidiabetic drugs on nonalcoholic fatty liver and steatohepatitis: think out of the box? Metabolism. 2019;101:154001.

43. Monteiro P, Bergenstal RM, Toural E, Inzucchi SE, Zinman B, Hantel S, et al. Efficacy and safety of empagliflozin in older patients in the EMPA-REG OUTCOME® trial. Age Ageing. 2019;48:859-66.

44. Onoviran OF, Li D, Smith ST, Raji MA. Effects of glucagon-like peptide 1 receptor agonists on comorbidities in older patients with diabetes mellitus. Ther Adv Chronic Dis. 2019;10:12;10:2040622319862691.

45. Martinez FA, Serenelli M, Nicolau JC, Petrie MC, Chiang CE, Tereshchenko $S$, et al. Efficacy and safety of dapagliflozin in heart failure with reduced ejection fraction according to age: insights from DAPA-HF. Circulation. 2020;141:100-11.

46. Gómez-Huelgasa R, Díez-Espinob J, Formigac $F$, Tejedord JL, Mañase LR, González-Sarmientoa E, et al. Tratamiento de la diabetes mellitus Tipo 2 en el paciente anciano. Rev Clin Esp. 2018;218:74-88.

47. Ritzel R, Roussel R, Giaccari A, Vora J, Brulle-Wohlhueter C, Yki-Järvinen $\mathrm{H}$. Better glycaemic control and less hypoglycaemia with insulin glargine $300 \mathrm{U} / \mathrm{mL}$ vs glargine $100 \mathrm{U} / \mathrm{mL}$ : 1 -year patient-level meta-analysis of the EDITION clinical studies in people with Type 2 diabetes. Diabetes Obes Metab. 2018;20:541-8.

48. Turner R. Effect of intensive blood-glucose control with metformin on complications in overweight patients with Type 2 diabetes (UKPDS 34). Lancet. 1998;352:854-65.

49. Gerstein HC, Miller ME, Byington RP, Goff DC Jr., Bigger JT, Buse JB, et al. Effects of intensive glucose lowering in Type 2 diabetes. $\mathrm{N}$ Engl $\mathrm{J}$ Med. 2008;358:2545-59.

50. Duckworth W, Abraira C, Moritz T, Reda D, Emanuele N, Reaven PD, et al. Glucose control and vascular complications in veterans with Type 2 diabetes. N Engl J Med. 2009;360:129-39.

51. ADVANCE Collaborative Group, Patel A, MacMahon S, Chalmers J, Neal B, Billot L, Woodward M, et al. Intensive blood glucose control and vascular outcomes in patients with Type 2 diabetes. $\mathrm{N}$ Engl $\mathrm{J}$ Med. 2008;358:2560-72

52. Mach F, Baigent C, Catapano AL, Koskinas KC, Casula M, Badimon L, et al. 2019 ESC/EAS guidelines for the management of dyslipidaemias: lipid modification to reduce cardiovascular risk. Eur Heart J. 2019;41:111-88

53. Varin EM, McLean BA, Lovshin JA Glucagon-like peptide-1 receptor agonists in adult patients with Type 2 diabetes : review of cardiovascular outcome trials. Can J Diabetes. 2019;44:68-77.

54. Furtado RH, Bonaca MP, Raz I, Zelniker TA, Mosenzon O, Cahn A, et al. Dapagliflozin and cardiovascular outcomes in patients with Type 2 diabetes mellitus and previous myocardial infarction. Circulation. 2019;139:2516-27.

55. Zelniker TA, Wiviott SD, Raz I, Im K, Goodrich EL, Bonaca MP, et al. SGLT2 inhibitors for primary and secondary prevention of cardiovascular and renal outcomes in Type 2 diabetes: a systematic review and meta-analysis of cardiovascular outcome trials. Lancet. 2019;393: 31-9.

56. Bain S, Druyts E, Balijepalli C, Baxter CA, Currie CJ, Das R, et al. Cardiovascular events and all-cause mortality associated with sulphonylureas compared with other antihyperglycaemic drugs: a Bayesian meta-analysis of survival data. Diabetes Obes Metab. 2017;19:329-35. 